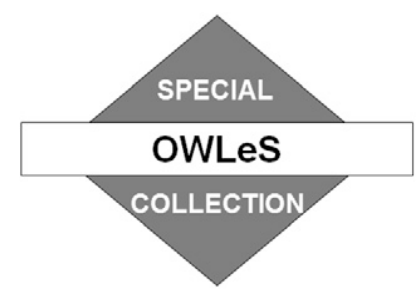

\title{
Predicting the Inland Penetration of Long-Lake-Axis-Parallel Snowbands
}

\author{
Daniel T. Eipper, George S. Young, Steven J. Greybush, and Seth Saslo \\ Department of Meteorology and Atmospheric Science, The Pennsylvania State University, University Park, Pennsylvania \\ TODD D. SIKORA AND RICHARD D. CLARK \\ Department of Earth Sciences, Millersville University, Millersville, Pennsylvania
}

(Manuscript received 23 February 2018, in final form 16 June 2018)

\begin{abstract}
Predicting the inland penetration of lake-effect long-lake-axis-parallel (LLAP) snowbands is crucial to public safety because LLAP bands can produce hazardous weather well downwind of the parent lake. Accordingly, hypotheses for the variation in inland penetration of LLAP-band radar echoes (InPen) are formulated and tested. The hypothesis testing includes an examination of statistical relationships between environmental variables and InPen for 34 snapshots of LLAP bands observed during the Ontario Winter Lake-effect Systems (OWLeS) field campaign. Several previously proposed predictors of LLAP-band formation or InPen demonstrate weak correlations with InPen during OWLeS. A notable exception is convective boundary layer (CBL) depth, which is strongly correlated with InPen. In addition to CBL depth, InPen is strongly correlated with cold-air advection in the upper portion of the CBL, suggesting that boundary layer destabilization produced by vertically differential cold-air advection may be an important inland power source for preexisting LLAP bands. This power production is quantified through atmospheric energetics and the resulting variable, differential thermal advection power (DTAP), yields reasonably skillful predictions of InPen. Nevertheless, an InPen model developed using DTAP is outperformed by an empirical model combining CBL depth and potential temperature advection in the upper portion of the CBL. This two-variable model explains $76 \%$ of the observed InPen variance when tested on independent data. Finally, implications for operational forecasting of InPen are discussed.
\end{abstract}

\section{Introduction}

Lake-effect long-lake-axis-parallel (LLAP) snowbands ${ }^{1}$ are known to produce heavy snowfall downwind of the Great Lakes (Jiusto and Kaplan 1972; Niziol et al. 1995; Veals and Steenburgh 2015; Campbell et al. 2016). Consequently, accurately predicting the inland extent of LLAP-band snowfall is important for public safety (e.g., Villani et al. 2017). Although LLAP bands have been studied for several decades (e.g., Peace and Sykes 1966; Holroyd 1971; Kelly 1986; Hjelmfelt 1990; Byrd et al. 1991; Niziol et al. 1995; Ballentine et al. 1998; Laird et al. 2003b; Steiger et al. 2013; Veals and Steenburgh 2015;

\footnotetext{
${ }^{1}$ LLAP bands have also been studied under different names, such as type I snowbands by Niziol et al. (1995).

Corresponding author: Daniel T. Eipper,dte108@psu.edu
}

Minder et al. 2015; Campbell et al. 2016; Bergmaier et al. 2017), research has focused primarily on LLAP bands over the parent lake or over land areas relatively close to the lake (Villani et al. 2017). However, LLAP-band snowfall has been observed to extend hundreds of kilometers inland on occasion (Niziol et al. 1995; Villani et al. 2017), underscoring the need for accurate understanding and forecasting of LLAP-band inland penetration. In this study we pursue this quest by investigating physical mechanisms and environmental predictors supportive of the inland penetration of LLAP-band radar echoes (hereafter InPen).

Previous lake-effect studies have established the fundamental requirement for lake-effect convection to be the flow of a sufficiently cold air mass over a relatively warm lake surface (e.g., Phillips 1972; Lenschow 1973; Dewey 1979; Niziol 1987; Kristovich and Laird 1998; Kristovich et al. 2003). The resulting fluxes of sensible 


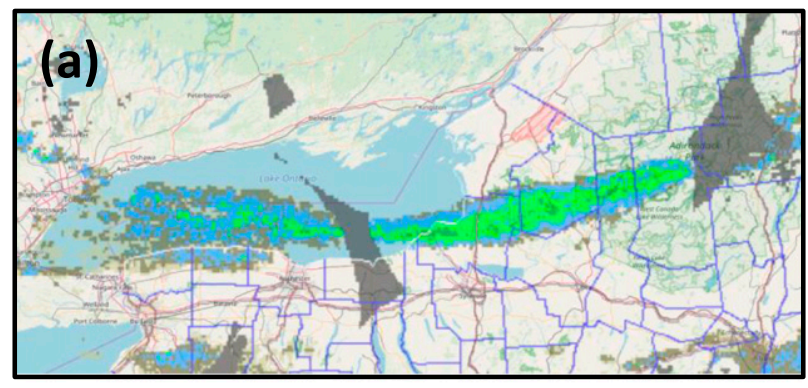

1800 UTC 27 January 2014
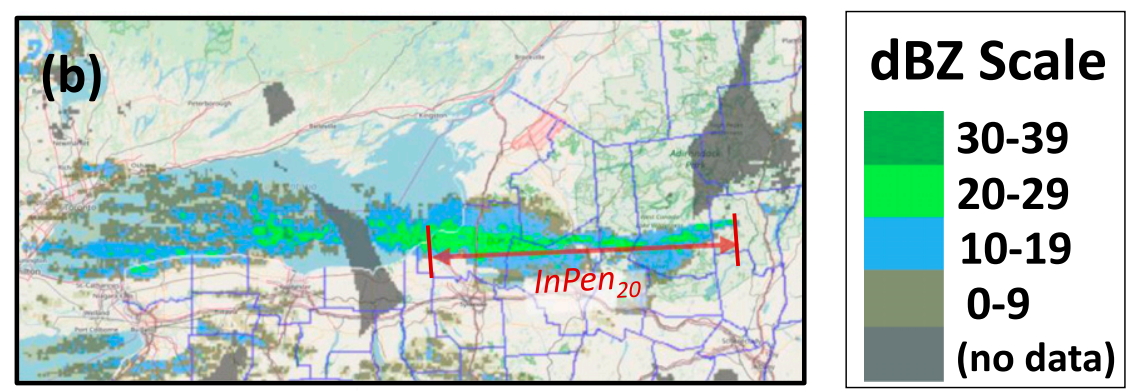

2000 UTC 27 January 2014

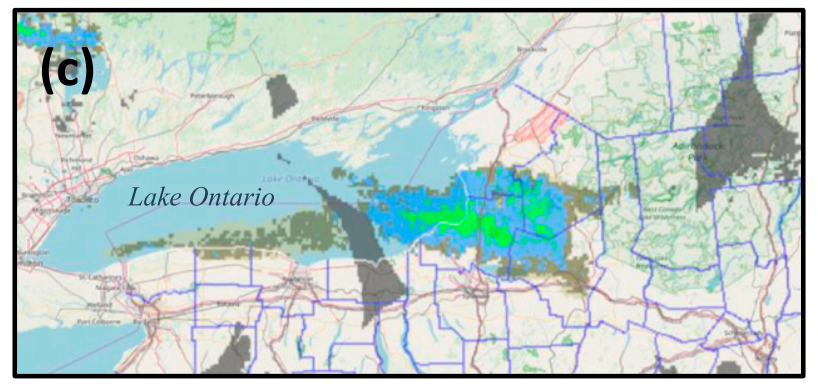

\section{UTC 28 January 2014}

FIG. 1. NEXRAD equivalent radar reflectivity factor (reflectivity) images, depicting an LLAP band at three different times. Images are 4000-ft CAPPI displays. Note the large difference in inland penetration of reflectivity between (a) or (b) and (c). The method for measuring InPen $_{20}$ is illustrated in (b).

and latent heat from the lake surface into the overlying air lead to rapid heating, moistening, and growth of the boundary layer and to the development of boundary layer convection (e.g., Lenschow 1973; Agee and Gilbert 1989; Chang and Braham 1991; Kristovich and Laird 1998; Kristovich et al. 2003). The convective organization is strongly influenced by the wind vector within the convective boundary layer (CBL; e.g., Holroyd 1971; Passarelli and Braham 1981; Hjelmfelt 1990; Kristovich 1993; Niziol et al. 1995; Laird et al. 2003a,b; Miles and Verlinde 2005a,b). Specifically, when the CBL mean wind is approximately aligned with the long axis of an elliptical lake, an LLAP band can form (see Fig. 1; e.g.,
Niziol 1987; Niziol et al. 1995; Ballentine et al. 1998; Steiger et al. 2013; Minder et al. 2015; Veals and Steenburgh 2015; Welsh et al. 2016).

An LLAP band contains a vigorous mesoscale solenoidal circulation (MSC), resulting from 1) the long overlake fetch, which leads to extensive thermodynamic modification of the CBL, and 2) the wind direction/ shoreline configuration, which ensures the proximity of colder, unmodified air on either side of the lakemodified plume (e.g., Peace and Sykes 1966; Hjelmfelt 1990; Niziol et al. 1995; Bergmaier et al. 2017). The MSC contains the fundamental elements of low-level CBL convergence (as cooler air intrudes into the lake-heated 
warm core), midlevel CBL ascent, and upper-level CBL divergence. Notwithstanding these commonalities, the full kinematic structure may exhibit additional layers of complexity, including asymmetric low-level CBL inflow and variations in the degree to which the strongest convection is organized into a discrete line or is distributed over a wider swath (Peace and Sykes 1966; Steiger et al. 2013; Minder et al. 2015; Campbell et al. 2016; Welsh et al. 2016; Kristovich et al. 2017). Studies of LLAP bands have also demonstrated the sensitivity of LLAP-band intensity to lake-induced low-level instability, CBL vertical wind shear, CBL depth, and synoptic-scale forcing (Holroyd 1971; Niziol 1987; Byrd et al. 1991; Niziol et al. 1995; Ballentine et al. 1998; Campbell et al. 2016).

An important focus of recent research has been the often-dramatic enhancement of lake-effect snowfall over the Tug Hill Plateau, which lies east of Lake Ontario (e.g., Veals and Steenburgh 2015). The recent Ontario Winter Lake-effect Systems (OWLeS) field campaign from December 2013 to January 2014 (Kristovich et al. 2017) has led to unprecedented insight into the structure and behavior of LLAP bands before, during, and shortly after landfall (Minder et al. 2015; Campbell et al. 2016; Welsh et al. 2016; Bergmaier et al. 2017; Campbell and Steenburgh 2017; Steenburgh and Campbell 2017). For example, new results indicate that precipitation enhancement over the Tug Hill Plateau is related, at least in part, to enhanced stratiform ascent rather than to orographic invigoration of convective updrafts (Minder et al. 2015; Welsh et al. 2016) and is also sensitive to the degree of organization of lake-effect bands (Campbell et al. 2016).

Research on the inland penetration of LLAP bands is complementary to these recent LLAP-band studies, given observations of LLAP bands extending well beyond the Tug Hill Plateau on occasion (e.g., Niziol et al. 1995; Villani et al. 2017). Figure 1 shows the contrast between the same LLAP band at times of large InPen (Figs. 1a,b) and a time of limited InPen (Fig. 1c).

To further motivate the topic of inland penetration, we offer a brief discussion on the relationship between the reflectivity values used in InPen measurements (these measurements are explained in section 2) and snowfall rates. The decision to use reflectivity to estimate the inland extent of LLAP-band snowfall was motivated by the scarcity of surface data characterizing far-inland Lake Ontario LLAP bands. Although estimates of snowfall rate from reflectivity are subject to considerable uncertainty (e.g., Rasmussen et al. 2003), recent studies of Lake Ontario LLAP bands (Minder et al. 2015; Campbell et al. 2016) found the reflectivityliquid precipitation equivalent (LPE) relationship developed by Vasiloff (2002) to correspond favorably with manual observations. This relationship is

$$
Z=75 S^{2}
$$

where $Z$ is reflectivity (here in $\mathrm{mm}^{6} \mathrm{~mm}^{-3}$ rather than $\mathrm{dBZ}$ ) and $S$ is the LPE rate $\left(\mathrm{mm} \mathrm{h}^{-1}\right)$. After LPE rates are obtained from reflectivity, snowfall rates may be estimated by applying a suitable snow-to-liquid ratio (SLR). SLRs are known to exhibit a high degree of variability based on a variety of factors [see Baxter et al. (2005) and the references therein]; for this illustration we use an SLR of 16.24 measured by Campbell et al. (2016) during an OWLeS LLAP-band event. Using these parameters, reflectivity values of 10,20 , and $30 \mathrm{dBZ}$ (each of which were frequently observed during OWLeS events) correspond respectively to LLAP-band snowfall rates of approximately $0.6,1.9$, and $5.9 \mathrm{~cm} \mathrm{~h}^{-1}$. Despite the uncertainties in these snowfall rates, this discussion indicates LLAP bands such as the one depicted in Fig. 1 are capable of producing heavy inland snowfall rates, which in turn are likely to result in significant social and economic impacts.

The topic of inland penetration has recently been examined by Villani et al. (2017), who emphasize that accurate and timely prediction of the inland extent of snowbands is an essential component to successful lakeeffect forecasts by the National Weather Service and has important repercussions for public safety. Villani et al. (2017) conducted a detailed evaluation of statistical relationships between a number of atmospheric variables and the inland extent of LLAP bands. A key finding is that inland extent is strongly correlated with the band's connection to an upwind Great Lake, indicating the important influence of upstream modification on LLAPband inland extent. In addition, the authors develop a 14-variable statistical model for predicting inland extent [see their Eqs. (1a)-(1c)] that explains nearly threequarters of the observed variance in the predictand. This model marks a pivotal milestone in the generation of quantitative forecasts of inland extent/penetration.

The present study, performed independently of the study by Villani et al. (2017), complements the latter by exploring alternative InPen definitions and a different methodology and by critically examining several hypotheses and physical mechanisms for InPen. In particular, we investigate the role of vertically differential temperature advection on InPen, which is not addressed by Villani et al. (2017). Additional insight into the largescale predictors of InPen will further equip forecasters to accurately leverage observations and numerical weather prediction (NWP) model guidance.

In the remainder of the paper, we first describe the datasets and data processing techniques used in this 


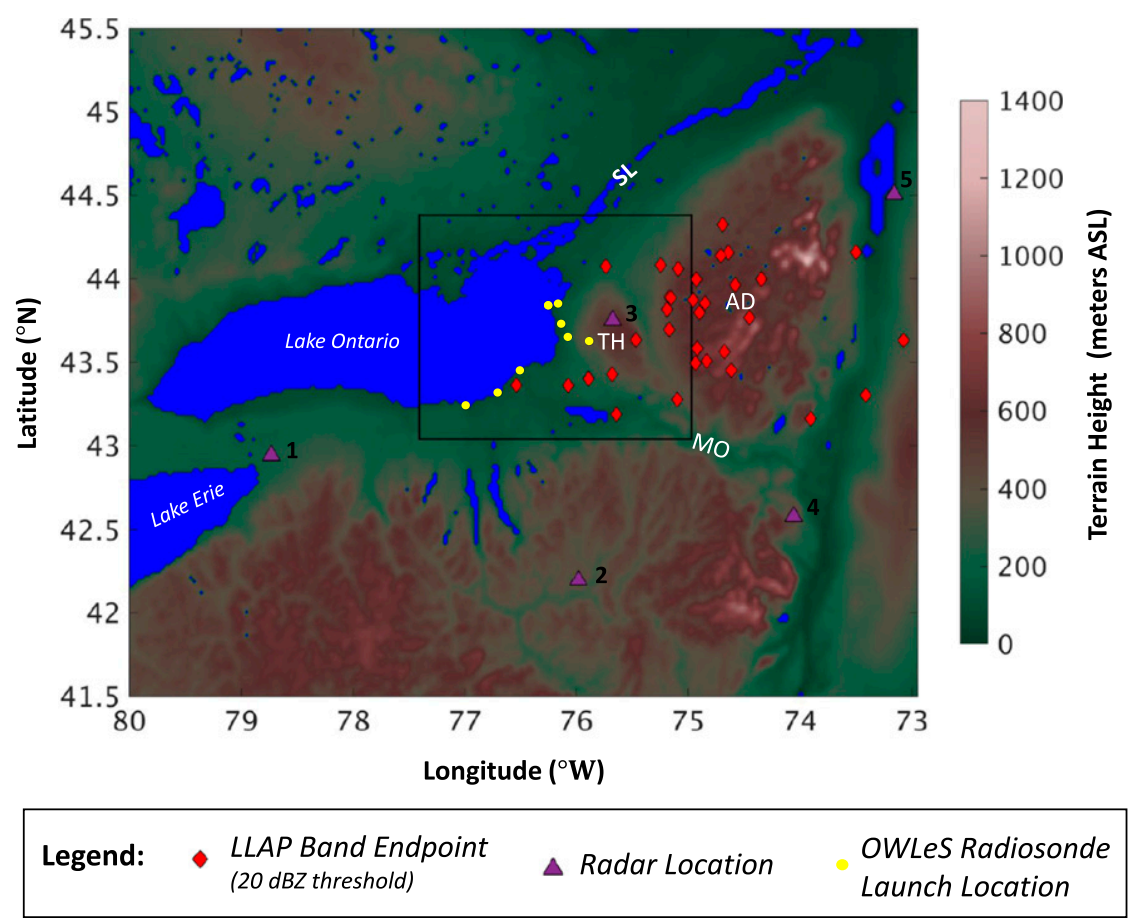

FIG. 2. Geographic and topographic features and terrain height (m MSL) of the study region, with LLAP-band endpoints plotted. The white letters denote the following topographic features: TH, Tug Hill Plateau; SL, Saint Lawrence valley; MO, Mohawk Valley; and $\mathrm{AD}$, the Adirondacks. The red diamonds mark the endpoints of LLAP bands at the 20-dBZ threshold used in this study (i.e., InPen 20 points). The black rectangle outlines the NARR averaging rectangle used in this study. The yellow circles mark the approximate launch locations of OWLeS research radiosondes used to corroborate the NARR data. The purple triangles and associated black numbers denote the locations of the NEXRAD sites that contributed to the reflectivity images used in the study, with the numbers representing the following sites: 1, Buffalo, NY (KBUF); 2, Binghamton, NY (KBGM); 3, Montague, NY (KTYX); 4, Albany, NY (KENX); and 5, Burlington, VT (KCXX).

study. We then investigate physical mechanisms and environmental conditions supporting InPen of Lake Ontario LLAP bands observed during OWLeS. Finally, we develop and test InPen models and discuss the implications of this research.

\section{Data and processing}

To perform statistical analysis on InPen, InPen needed first to be quantified. This process began with the identification of Lake Ontario LLAP bands. For LLAPband identification, we employed 4000-ft NEXRAD constant-altitude plan position indicator (CAPPI) images of equivalent radar reflectivity factor (hereafter reflectivity; see Fig. 1 for examples). The NEXRAD CAPPI images were obtained from OWLeS archives at the NCAR Earth Observing Laboratory (EOL; www. eol.ucar.edu/field_projects/owles). These images were developed from multiple NEXRAD sites, the locations of which are shown in Fig. 2. The choice of the 4000-ft level avoided coverage gaps at the 2000-ft level and overshooting at the 6000-ft level. All LLAP-band samples were selected from December 2013 and January 2014, approximately the date interval of the OWLeS field program (Kristovich et al. 2017). The decision to use these dates was made in part to ensure access to the CAPPI images stored by the EOL; in addition, the OWLeS field project occurred during an exceptionally active season for LLAP bands (Kristovich et al. 2017).

Our strategy for identifying LLAP-band samples, or snapshots, began with inspecting CAPPI reflectivity images every $3 \mathrm{~h}$, to match the output frequency of the North American Regional Reanalysis (NARR; discussed below). We first determined hours for which the reflectivity image revealed one or, at most, $\mathrm{two}^{2}$ dominant lake-effect bands with widths of $\sim 20-40 \mathrm{~km}$ [after

\footnotetext{
${ }^{2}$ See Veals and Steenburgh (2015) for a discussion of occasional dual-LLAP bands.
} 
Niziol et al. (1995) and Steiger et al. (2013)] extending inland from Lake Ontario. Because we required one or two bands to dominate the reflectivity field rather than that there be no other echoes present, it is likely our analysis included some instances with LLAP band/broad coverage hybrid morphologies (Veals and Steenburgh 2015). However, we ensured a focus on banded lake-effect structures by requiring, in addition to the width criterion, the highest reflectivity values (e.g., values $\geq 20 \mathrm{dBZ}$ ) within each reflectivity feature to be arranged either in a quasi-linear continuous band (i.e., a "line") or as discrete cells within a quasi-linear ribbon (see Fig. 1 for examples). Next, to verify that each Lake Ontario dominant band was also a LLAP band according to previous definitions (e.g., Steiger et al. 2013; Minder et al. 2015; Veals and Steenburgh 2015; Welsh et al. 2016; Steenburgh and Campbell 2017), it was required that 1 ) the band be roughly aligned with (within $\sim 20^{\circ}$ of) the long axis of Lake Ontario and 2) the NARR 850-hPa area-averaged wind vector be approximately parallel to the band. Bands meeting these criteria were classified as LLAP bands, and reflectivity images containing them were termed LLAP-band snapshots.

Following the LLAP-band identification step, the set of snapshots was thinned to a maximum frequency of one snapshot every $6 \mathrm{~h}$. This thinning was implemented in an effort to maintain independence between snapshots. Six hours was used as a minimum sample separation because LLAP bands were commonly observed to undergo extensive morphological evolution in under $6 \mathrm{~h}$. For LLAP-band events with a series of snapshots each $3 \mathrm{~h}$ apart, thinning was performed by retaining the odd-numbered snapshots (e.g., first, third, fifth, etc.). This rule, though arbitrary, maximized the number of snapshots included in the analysis for events in which the number of original snapshots (those taken every $3 \mathrm{~h}$ ) was an odd number. The end result of the identification and thinning steps was a set of 34 LLAP-band snapshots.

Following the selection of LLAP-band snapshots, InPen was measured for each snapshot at 10-, 20-, and $30-\mathrm{dBZ}$ thresholds, defined as $\operatorname{InPen}_{10}$, InPen $_{20}$, and InPen $_{30}$, respectively. These thresholds span the range of significant reflectivity values typically observed during OWLeS and available on the CAPPI images. The instantaneous value of InPen for a given reflectivity threshold was defined as the distance from the band landfall point to the farthest-inland occurrence, in the 4000-ft CAPPI image, of that reflectivity value within the structurally continuous LLAP band; Fig. 1b illustrates an InPen $_{20}$ measurement. Structural continuity was most commonly verified by requiring reflectivity features to be located within the closed 0 -dBZ contour (at the 4000-ft level), which contained the highest-reflectivity core of the LLAP band at landfall. However, in a few instances, bands appeared to potentially extend through a region where $4000-\mathrm{ft}$ radar coverage was unavailable; in these instances, $6000-\mathrm{ft}$ CAPPI images and/or visible satellite images were consulted to verify structural continuity. When, on the other hand, a higher-reflectivity core appeared to terminate in a region where $4000-\mathrm{ft}$ radar coverage was unavailable (as indicated by the corresponding $6000-\mathrm{ft}$ CAPPI image), InPen was considered indeterminate and the snapshot was discarded (this situation occurred for one potential snapshot). InPen was measured along the approximate axis of the LLAP band using a distance-measuring tool available on the EOL graphical user interface. To reduce noise in InPen measurements, the recorded value of InPen was defined as the 1-h mean of five instantaneous InPen values (the instantaneous value at the measurement time and at 15 and $30 \mathrm{~min}$ before and after this time).

Our decision to use the farthest-inland occurrence of each reflectivity value to measure InPen, rather than a contiguous region containing the band core at landfall, was motivated by a consideration of societal impacts. Regions with reflectivity values at or above $20 \mathrm{~dB} Z$, for example, can be expected to produce significant snowfall rates whether they are contiguous or are separated by intervening regions with lower reflectivity values (e.g., Fig. 1b). Meanwhile, the structural continuity requirement ensures that each higher-reflectivity region occurs within the parent LLAP band. This definition of InPen marks an important distinction between this study and that of Villani et al. (2017). Villani et al. (2017) define inland extent as the distance inland to the terminus of a contiguous band of $15-\mathrm{dBZ}$ (or greater) reflectivity. Consequently, this study provides a complementary focus to that of Villani et al. (2017) by placing greater emphasis on processes that invigorate far-inland portions of LLAP bands (e.g., illustrated in Fig. 1b).

Upon investigation, we obtained strong relationships between InPen $_{10}$, InPen 20 , and InPen ${ }_{30}$, with correlation coefficients above 0.79 and $p$ values $<0.01$. A two-tailed probability test (Wilks 2006) was used to determine the statistical significance (measured with $p$ values) of the correlation coefficients computed in this study. In the following analysis we use InPen $_{20}$ as the study predictand. Based on the discussion in section 1 on the relationship between reflectivity values and snowfall rates, InPen $_{20}$ encompasses those inland portions of LLAP bands with snowfall rates approximately $\geq 1.9 \mathrm{~cm} \mathrm{~h}^{-1}$.

Data from the NARR (Mesinger et al. 2006) were used to characterize the synoptic environment for each LLAP snapshot. The relatively coarse horizontal 
resolution of the NARR $(\sim 32 \mathrm{~km})$ was considered to be advantageous for this study because it fully resolves the synoptic pattern without resolving some of the mesoscale features (e.g., the LLAP band's own circulation), which could obscure the synoptic signal. This attribute was important because several NARR-generated synoptic variables were tested as InPen predictors and LLAP bands frequently contain strong mesoscale circulations (Peace and Sykes 1966; Steiger et al. 2013; Welsh et al. 2016).

As an additional precaution against the synoptic pattern being obscured by mesoscale circulations, we computed NARR variables as horizontal-mean values within a rectangle centered over the eastern shore of Lake Ontario. This averaging rectangle is shown in Fig. 2; it extends approximately $100 \mathrm{~km}$ east and west from Lake Ontario's eastern shoreline and $25 \mathrm{~km}$ inland from both its southern and northern shorelines (specifically, $74.97^{\circ}-77.41^{\circ} \mathrm{W}$ and $43.04^{\circ}-44.38^{\circ} \mathrm{N}$ ). The zonal dimension was selected to represent the synoptic environment of LLAP bands as they intensify over the eastern portion of Lake Ontario and begin to penetrate inland. The meridional dimension was selected in an effort to encompass the entire north-south extent of the MSC (primary and return flows) and so minimize the influence of the MSC on the synoptic signal. It was also crucial that both dimensions were small enough to not produce blurring of the synoptic signal. Accordingly, the rectangle dimensions were also chosen as a conservative size for adequately resolving the lake-scale environment created by $O(2000) \mathrm{km}$ synoptic-scale waves (Orlanski 1975), while simultaneously averaging out smaller scales.

NARR variables used to characterize the synoptic environment included temperature, potential temperature $\theta$, and horizontal wind. To corroborate the NARR data, wind and temperature profiles derived from the NARR dataset were compared with research radiosondes launched during OWLeS. Figure 2 illustrates the launch locations of radiosondes used in this corroboration step. The comparison revealed height-matched CBL temperatures that typically differed by $\leq 2 \mathrm{~K}$ and wind vectors within a few meters per second. Note that the mesoscale structure and strong circulation of LLAP bands (e.g., Peace and Sykes, 1966; Byrd et al. 1991; Steiger et al. 2013; Welsh et al. 2016) make exact agreement between observations and area-averaged NARR profiles unlikely.

In addition, lake-surface sensible and latent heat fluxes were obtained from the NARR. The NARR utilizes an operational version of the NCEP regional Eta Model (e.g., Mesinger et al. 1988; Janjić 1994) and the Eta Data Assimilation System (EDAS; e.g., Black 1994; Rogers et al. 2001). The NARR uses the Mellor-Yamada level 2.0 scheme (Mellor and Yamada 1974; 1982) to parameterize the surface layer, with a viscous sublayer over water surfaces (e.g., Black 1994). NARR surface fluxes are calculated using Monin-Obukov functions in conjunction with the Mellor-Yamada level 2.0 scheme; additional details are provided in Black (1994). In addition, NARR uses an updated version of the Noah land surface model (e.g., Ek et al. 2003; Mesinger et al. 2006). Most unstable convective available potential energy (MUCAPE) was also obtained from the NARR (Gensini and Ashley 2011; Lombardo and Colle 2011). Both heat fluxes and MUCAPE were averaged for the overlake portion of the NARR averaging rectangle.

A number of methods, both manual and automated, exist for determining the top of the boundary layer (e.g., Barr and Betts 1997; Seibert et al. 2000; Schmid and Niyogi 2012), and have been applied in lake-effect studies (e.g., Holroyd 1971; Villani et al. 2017). While the NARR computes planetary boundary layer height diagnostically using equilibrium turbulent kinetic energy (Schmid and Niyogi 2012), we preferred to use the $\theta$ criterion of Barr and Betts (1997), which is based on a straightforward thermodynamic interpretation of the CBL. Specifically, the CBL top (or $Z_{i}$ ) was determined manually as the lowest level within a layer lying atop a well-mixed layer in which $\partial \theta / \partial z$ became markedly more positive (below $Z_{i}$, the area-averaged $\theta$ profile was often close to moist adiabatic with small positive values of $\partial \theta / \partial z$ ); the reader is referred to Barr and Betts (1997) for additional information.

Finally, lake surface temperatures were used to compute temperature differences between the lake surface and the atmosphere at the $850-$ and $700-\mathrm{hPa}$ levels. Lake surface temperatures were obtained from NCEP real-time global sea surface temperature analyses (Thiébaux et al. 2003; available online at http://polar. ncep.noaa.gov/sst/rtg_high_res/). While we did not test for biases in the temperature analyses, this possible source of error is recommended as a topic for further examination.

\section{Analysis}

We begin our analysis with an examination of three hypotheses for the inland penetration of LLAP bands and then move on to the development of regression models for InPen.

\section{a. Examination of hypotheses for InPen}

\section{1) AdVECTION-ONLY HYPOTHESIS}

In the absence of any mechanism for enhancing the inland penetration of LLAP bands, a reasonable 
hypothesis is that InPen will be proportional to the inland advection of LLAP-band elements (e.g., overturning MSC, falling hydrometeors). We termed this hypothesis the advection-only hypothesis and examined its ability to explain InPen.

Starting from the advection-only hypothesis, a basic particle trajectory model for InPen can be constructed. This particle trajectory model, hereafter referred to as the up-down model, assumes the inland penetration of lake-effect snow will be the sum of the distance individual lake-effect parcels are advected inland during buoyant ascent (ascent advection distance) and the distance hydrometeors are advected during fallout after buoyancy has been exhausted (fallout advection distance). In addition, the up-down model assumes the farthest-penetrating lake-effect parcels begin their ascent at the downwind shore (the downwind terminus of buoyancy generation under the advection-only hypothesis) and ascend at constant speed. Thus, the equation for snow particle trajectory distance is given by

$$
\begin{aligned}
\text { InPen }_{\text {up-down }}= & (\text { ascent advection distance }) \\
& +(\text { fallout advection distance })
\end{aligned}
$$

We defined

$$
\text { ascent advection distance }=U_{850} \Delta Z_{\mathrm{CBL}} / w_{*},
$$

where $U_{850}$ is the wind speed at $850 \mathrm{hPa}, \Delta Z_{\mathrm{CBL}}$ is the depth of the CBL $\left(\Delta Z_{\mathrm{CBL}}=Z_{i}-Z_{\mathrm{sfc}}\right.$, where $Z_{\mathrm{sfc}}$ is the terrain height), and $w_{*}$ is the free-convection scaling velocity (Stull 1988). The free-convection scaling velocity is an estimate of updraft velocity based on boundary layer theory and was approximated as $w_{*} \approx\left[\left(g \Delta Z_{\mathrm{CBL}} / \theta_{v_{-} s}\right) F_{s}^{H}\right]^{1 / 3}$, where $g$ is the gravitational constant, $\theta_{v_{-} s}$ is the near-surface virtual potential temperature, and $F_{s}^{H}$ is the surface kinematic sensible heat flux (an alternative estimate of updraft velocity, based on convective available potential energy, is discussed later in this section). For each snapshot, values of $U_{850}$ and $\Delta Z_{\mathrm{CBL}}$ were obtained from the area-averaged NARR data (described in section 2$) ; w_{*}$ was calculated from the overlake portion of the NARR averaging rectangle using lake-surface heat fluxes. In addition, $U_{850}$ was used as a proxy for the mean CBL wind speed. The $U_{850}$ tended to overestimate the mean CBL wind speed, since $Z_{i}$ was frequently near $850 \mathrm{hPa}$ and the wind speed generally decreased between $850 \mathrm{hPa}$ and the surface. While no attempt was made to scale $U_{850}$ or other variables directly, in a later application of the model (see section 3b), regression calculations removed systematic biases in InPen $_{\text {up-down, ascent advection }}$ distance, and fallout advection distance. In a similar manner to ascent advection distance, fallout advection distance was defined as

$$
\text { fallout advection distance }=U_{850} \Delta Z_{\mathrm{CBL}} / w_{\text {fall }} \text {, }
$$

where $w_{\text {fall }}$ is the fall speed of lake-effect hydrometeors and was assumed to be constant at $1 \mathrm{~m} \mathrm{~s}^{-1}$ (e.g., Welsh et al. 2016).

When the up-down model was tested on the 34 LLAP-band snapshots, InPen ${ }_{\text {up-down }}$ achieved a correlation coefficient (hereafter correlation or $r$ ) with InPen $_{20}$ of 0.64 , which is statistically significant at the $99 \%$ confidence level ( $p$ value $<0.01$; see Table 1 , which also includes the individual correlation coefficients and statistical significance of ascent advection distance, fallout advection distance, and other variables discussed in section 3a). Despite the relatively strong correlation with InPen $_{20}$, the up-down model consistently resulted in large underestimates of $\operatorname{InPen}_{20}$; mean $\mathrm{InPen}_{\mathrm{up}-\text { down }}$ was approximately one-quarter mean $\operatorname{InPen}_{20}$. This underestimation is especially striking in view of the previously mentioned tendency for $U_{850}$ to overestimate the mean CBL wind speed. Note too that the up-down model, rather than serving merely as an InPen predictor, purports to give an actual computation of inland penetration. Thus, the serious underestimation of $\operatorname{InPen}_{20}$ by InPen $_{\text {up-down }}$ indicates that the rudimentary assumptions of the up-down model-and perhaps of the advection-only hypothesis - are inadequate. One concern with the up-down model is that LLAP bands are not composed only of independent convective-scale cells but contain strong MSCs (Peace and Sykes 1966; Steiger et al. 2013; Welsh et al. 2016).

To further investigate the advection-only hypothesis, we examined individually the relationships between $U_{850}$ and InPen $_{20}$ and between $\Delta Z_{\mathrm{CBL}}$ and InPen ${ }_{20}$. In addition to the inclusion of $U_{850}$ in the up-down model, boundary layer wind speed as a predictor of the inland extent of snowfall or lake-effect circulations is documented in Villani et al. (2017) and is also implied in Niziol et al. (1995) and in the numerical simulations of Sousounis (1993) and Laird et al. (2003b). The 850-hPa wind speed is positively correlated with InPen $_{20}$ for our dataset $(r=0.26)$, with a correlation coefficient similar to values obtained by Villani et al. (2017) for measurements between inland extent and mean mixed layer wind speed. The $r=0.26$ correlation is not statistically significant for our sample size $(p$ value $=0.14)$. Moreover, an InPen model using only $U_{850}$ as a predictor can explain less than $10 \%$ of the observed variance in InPen $_{20}$.

In contrast to $U_{850}, \Delta Z_{\mathrm{CBL}}$ exhibits a strong and statistically significant correlation with $\operatorname{InPen}_{20}(r=0.71$, 
TABLE 1. Correlation coefficients between InPen and hypothesis-related InPen predictors (see section 3a). Variables inside curly braces in the second column correspond to similarly denoted values in the third and fourth columns. Boldface font in the rightmost two columns indicates the correlation coefficients that are statistically significant at the $99 \%$ confidence level.

\begin{tabular}{|c|c|c|c|}
\hline Hypothesis & Variable & Correlation with InPen $_{20}$ & $p$ value \\
\hline \multirow[t]{10}{*}{ Advection only } & Ascent advection distance & 0.63 & $<\mathbf{0 . 0 1}$ \\
\hline & Fallout advection distance & 0.63 & $<\mathbf{0 . 0 1}$ \\
\hline & $\begin{array}{l}\text { InPen }_{\text {up-down }} \text { (ascent advection distance } \\
\text { plus fallout advection distance) }\end{array}$ & 0.64 & $<\mathbf{0 . 0 1}$ \\
\hline & Wind speed at $850 \mathrm{hPa}$ & 0.26 & 0.14 \\
\hline & Convective boundary layer depth & 0.71 & $<\mathbf{0 . 0 1}$ \\
\hline & Lake surface total \{sensible\} heat flux & $0.050\{0.010\}$ & $0.78\{0.95\}$ \\
\hline & Lake surface temp minus 850 -hPa temp & -0.20 & 0.26 \\
\hline & Lake surface temp minus $700-\mathrm{hPa}$ temp & 0.32 & 0.063 \\
\hline & MUCAPE & 0.44 & $<\mathbf{0 . 0 1}$ \\
\hline & $\begin{array}{l}\text { Strength of capping inversion ( } \theta \text { difference } \\
\left.\text { between } p_{Z_{i}}-50 \mathrm{hPa} \text { and } p_{Z_{i}}\right)\end{array}$ & -0.44 & $<\mathbf{0 . 0 1}$ \\
\hline Inland plume focusing & $\begin{array}{l}\text { Directional turning of wind \{absolute } \\
\text { value of directional turning\} between } \\
950 \mathrm{hPa} \text { and } Z_{i}\end{array}$ & $-0.30^{\mathrm{a}}\{0.071\}$ & $0.088\{0.69\}$ \\
\hline Inland invigoration & $\mathrm{DTAP}_{h}$ & 0.77 & $<\mathbf{0 . 0 1}$ \\
\hline
\end{tabular}

${ }^{a}$ The negative correlation coefficient indicates backing wind profiles and InPen are positively correlated.

$p$ value $<0.01)$. While both ascent advection distance and fallout advection distance are proportional to $\Delta Z_{\mathrm{CBL}}$, it is doubtful these physical links can fully explain the strong correlation between $\Delta Z_{\mathrm{CBL}}$ and $\mathrm{InPen}_{20}$. This argument follows from the finding that $\Delta Z_{\mathrm{CBL}}$ is more strongly correlated with $\operatorname{InPen}_{20}$ than is either distance variable, despite our attempt in the formulation of the latter to modulate $\Delta Z_{\mathrm{CBL}}$ by updraft speed and horizontal wind speed. Aside from its connection to the up-down model, a deeper CBL indicates a deeper layer of moisture available to LLAP bands [in typical nearsaturated conditions (e.g., Byrd et al. 1991; Reinking et al. 1993; Minder et al. 2015; Campbell et al. 2016)] and of snow generation through cloud microphysical processes. A deeper CBL also indicates higher values of CAPE for a given value of near-surface instability (resulting from lake-induced heating) and favors the development of stronger updrafts (e.g., Markowski and Richardson 2010). The correlation between $\Delta Z_{\mathrm{CBL}}$ and $\mathrm{InPen}_{20}$ in this study is notably different from the very weak correlations between the mixed-layer depth and inland extent ( $r$ values between 0.0 and 0.1 ) obtained by Villani et al. (2017). This difference could be related in part to the different definitions of InPen/inland extent and could thus indicate that a deep boundary layer is especially important to processes that invigorate the farinland portions of LLAP bands. However, the different correlations may also be related to the different methods used for determining boundary layer depth [Villani et al. (2017) determined the boundary layer top manually as the lower limit of the lowest isothermal layer on each sounding; our methodology is explained in section 2]. Additional exploration of the relationships between boundary layer depth and various InPen/inland extent variables is recommended for future work.

Finally, we explored whether additional factors previously found to contribute to the formation or maintenance of LLAP bands might also correlate with InPen. This line of exploration is related to the advection-only hypothesis under the supposition that vigorous and/or strongly organized LLAP bands-which may result from the factors examined below-could persist longer after leaving the parent lake, thereby allowing for greater advection inland. These LLAP-band factors include lake-surface heat fluxes, which are a measure of the energy supplied to the boundary layer by the lake surface (e.g., Agee and Gilbert 1989; Chang and Braham 1991; Kristovich and Laird 1998; Kristovich et al. 1999; Laird and Kristovich 2002; Kristovich et al. 2003). These factors also include the difference between the lake surface temperature and the temperature at 850 or $700 \mathrm{hPa}$, which multiple researchers have linked to the degree of lake-induced or lake-enhanced lowertropospheric instability (e.g., Holroyd 1971; Niziol 1987; Hjelmfelt 1990; Niziol et al. 1995; Ballentine et al. 1998, Villani et al. 2017). Also included was MUCAPE (introduced in section 2), which offers a more direct measure of the energy associated with this instability (e.g., Steiger et al. 2009; Markowski and Richardson 2010). As a note, we experimented with substituting an expression for the maximum vertical velocity, $w_{\max }=$ $\sqrt{2 \text { MUCAPE }}$ (e.g., Markowski and Richardson 2010), 
for $w_{*}$ in Eq. (3). However, under the $w_{\max }$ formulation, the correlation between ascent advection distance and InPen $_{20}$ was much weaker $(r=0.10)$ and statistically insignificant. Finally, we included the strength of the capping inversion because some studies have found a weak capping inversion to be supportive of LLAP-band intensity (e.g., Reinking et al. 1993; Niziol et al. 1995); this was measured by subtracting $\theta$ at $Z_{i}$ from $\theta$ at $50 \mathrm{hPa}$ above $Z_{i}$. Of these potential predictors, statistically significant correlations with $\operatorname{InPen}_{20}$ (see Table 1$)$ are achieved only by MUCAPE $(r=0.44, p$ value $<0.01)$ and the strength of the capping inversion $(r=-0.44$, $p$ value $<0.01)$. These results indicate that larger MUCAPE and a weaker capping inversion support not just the formation of LLAP bands, but also their inland penetration.

In summary, while our investigation of the advectiononly hypothesis is introductory in nature, the serious underestimation of $\mathrm{InPen}_{20}$ by $\mathrm{InPen}_{\text {up-down }}$ raises questions about the existence of additional mechanisms supporting InPen. At the same time, our results indicate the importance of a favorable thermodynamic environment-especially a deep CBL-to InPen 20 .

\section{2) INLAND PLUME-FOCUSING HYPOTHESIS}

A second hypothesis for InPen is that InPen is enhanced when the plume of buoyancy and moisture associated with the LLAP band is focused into a narrow ribbon downwind of the parent lake. This inland plumefocusing hypothesis follows the experience of operational forecasters as reported in Niziol et al. (1995). The authors also indicate the mechanism for focusing the plume could be either strong vertical alignment of the CBL wind or orographic channeling.

In support of the vertical wind-alignment mechanism, Niziol et al. (1995) found excessive CBL directional wind shear to be detrimental to LLAP bands and results in their disintegration into fields of widespread convection (also discussed in Niziol 1987). They suggest $30^{\circ}$ of CBL directional turning as the upper limit for viable LLAP bands. Moreover, they hypothesize that exceptionally well-aligned profiles of CBL wind contribute to concentrated plumes of moisture and instability and to enhanced InPen. We tested this hypothesis on our data and found that nearly all snapshots met the criterion of $\mathrm{CBL}$ directional turning being less than $30^{\circ}$. Thus, our finding corroborated the viability limit suggested by Niziol et al. (1995). However, the relationship between exceptionally well-aligned CBL wind profiles and large InPen was not supported. Rather, the absolute value of the directional wind turning within the CBL showed a near-zero $(r=0.07)$ and statistically nonsignificant correlation with $\operatorname{InPen}_{20}$. However, the signed value of the directional turning [with negative values indicate backing (counterclockwise turning) of the wind vector with height and vice versa] exhibited a modest negative correlation with $\operatorname{InPen}_{20}(r=-0.30)$. Although this correlation was not significant at the $95 \%$ confidence level ( $p$ value $=0.09$ ), this result hints at a positive relationship between InPen and backing wind profiles within the CBL. Note that backing profiles of the geostrophic wind indicate cold-air advection (CAA) via the thermal wind relationship.

The second mechanism hypothesized by Niziol et al. (1995) is an orographic channeling mechanism in which the Mohawk Valley channels lake-effect moisture and instability associated with Lake Ontario bands, thereby promoting InPen. Figure 2 illustrates the location of the Mohawk Valley and the 20-dBZ endpoints of the 34 LLAP-band snapshots. While two snapshots with extensive $\mathrm{InPen}_{20}$ have apparent trajectories near the northern rim of the Mohawk Valley, two other snapshots with extensive $\operatorname{InPen}_{20}$ have apparent trajectories passing over (or over the northern periphery) of the Tug Hill Plateau and over high terrain in the Adirondacks. A number of other LLAP band snapshots with lesser but still significant InPen $_{20}$ terminate in the Adirondacks. These data do not appear to support orographic channeling as the dominant mechanism driving InPen. However, the analysis afforded by 34 snapshots during one lake-effect season (albeit an active one) is considered too cursory to offer definitive conclusions.

\section{3) INLAND INVIGORATION HYPOTHESIS}

A third hypothesis regarding InPen is that InPen is enhanced through the inland invigoration of the LLAP band. One mechanism for inland invigoration was suggested by a pre-OWLeS satellite survey. This survey indicated a preferential occurrence of large InPen in those LLAP-band images taken soon after a cold frontal passage. This relationship hints that CAA by the horizontal components of the synoptic-scale wind may play a role in regulating InPen. Furthermore, CAA increasing with height within the CBL acts to destabilize the CBL (Banacos and Ekster 2010) and, thus, represents an energy source for preexisting LLAP bands, whether overlake or inland. A specific way (though not the only possible way) in which CAA increasing with height may invigorate inland LLAP bands is by destabilizing the anvil region of the band. The anvil region of a LLAP band typically persists downwind long after lakemodified near-surface buoyant parcels have ascended to their equilibrium levels; this anvil region is saturated and is often characterized by near-moist-adiabatic lapse rates (e.g., Byrd et al. 1991; Welsh et al. 2016; Campbell and Steenburgh 2017). In this near-neutral environment, 
CAA increasing with height may produce instability and convective overturning, likely leading to higher inland snowfall rates.

To further investigate the hypothesized relationship between vertically differential CAA and InPen, we developed a metric we term differential thermal advection power (DTAP) to quantify the effect of vertically differential potential temperature advection on CBL energy production. For atmospheric layers within the CBL that are absolutely neutral/unstable or for saturated layers that are conditionally neutral/unstable [as is frequently the case within LLAP bands (e.g., Byrd et al. 1991; Reinking et al. 1993; Minder et al. 2015; Campbell et al. 2016)], DTAP represents the maximum production rate of available potential energy (energy available for conversion into kinetic energy) resulting directly from synoptic-scale differential potential temperature advection. Readers are referred to the appendix for the derivation of DTAP. Based on the perceived influence of differential potential temperature advection by the horizontal components of the synoptic-scale wind, we computed values of $\mathrm{DTAP}_{h}$, which is the component of DTAP resulting from synoptic-scale vertically differential horizontal potential temperature advection. We determine $\mathrm{DTAP}_{h}$ as follows:

$\mathrm{DTAP}_{h} \equiv \max _{\mathrm{CBL}}\left\{\frac{g}{\langle\bar{\theta}\rangle} \int_{z_{l}}^{z_{u}}\left[\mathbf{V}_{h} \cdot \nabla_{h} \theta-\left(\mathbf{V}_{h} \cdot \nabla_{h} \theta\right)_{l}\right] d z\right\}$,

where $z_{l}$ and $z_{u}$ are arbitrary lower and upper boundaries, respectively (see below for further explanation); $\langle\bar{\theta}\rangle$ is the mean value of potential temperature between $z_{l}$ and $z_{u} ;-\mathbf{V}_{h} \cdot \nabla_{h} \theta$ is potential temperature advection by the horizontal wind (hereafter thermal advection) as a function of $z ;\left(-\mathbf{V}_{h} \cdot \nabla_{h} \theta\right)_{l}$ is thermal advection at $z_{l}$; and $\max _{\mathrm{CBL}}$ indicates the maximum value, within the CBL, of the expression within the curly braces. The maximum value is determined by checking all possible combinations of $z_{l}$ and $z_{u}$, such that $z_{l}<z_{u} \leq Z_{i}$. DTAP was computed for individual horizontal grid points and then averaged over the NARR averaging rectangle. Equation (5) reveals that increased energy production rates (increased $\mathrm{DTAP}_{h}$ ) can result either from increased values of $\mathbf{V}_{h} \cdot \nabla_{h} \theta-\left(\mathbf{V}_{h} \cdot \nabla_{h} \theta\right)_{l}$ between $z_{l}$ and $z_{u}$ (note that positive values of $\mathbf{V}_{h} \cdot \nabla_{h} \theta$ indicate CAA) or from a deeper layer of differential thermal advection.

To evaluate the importance of $\mathrm{DTAP}_{h}$ for LLAP bands, we compared DTAP $_{h}$ with the power supplied by lake surface heat fluxes. While lake surface heat fluxes occur only over the lake, they are a fundamental driver of lake-effect convection (e.g., Lenschow 1973; Chang

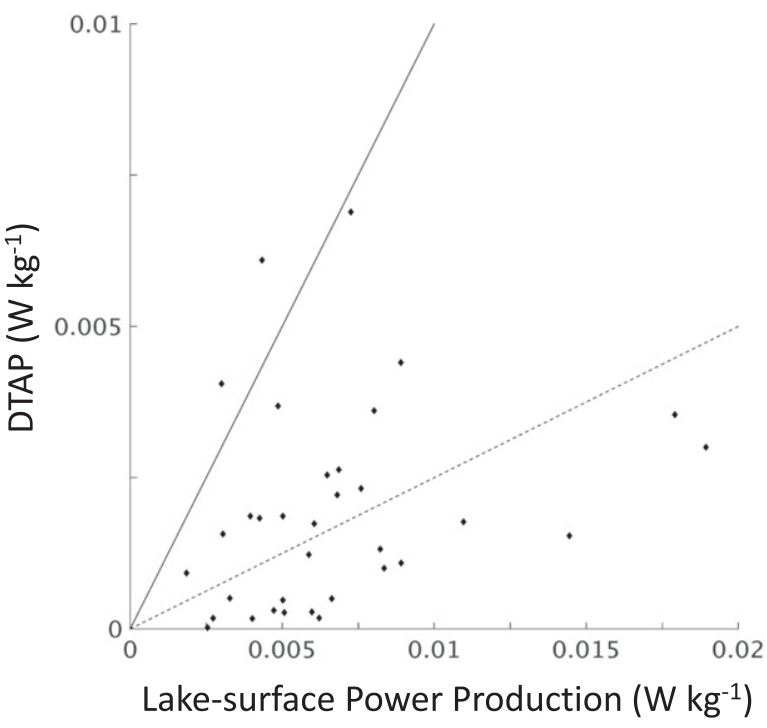

FIG. 3. Scatterplot of DTAP vs lake surface power production for all LLAP-band snapshots. A solid line with a slope of unity and a dashed line with a slope of one-quarter are included to facilitate comparison between the two power sources. The mean value of lake surface power production is $6.7 \times 10^{-3} \mathrm{~W} \mathrm{~kg}^{-1}$, and the mean value of DTAP is $1.9 \times 10^{-3} \mathrm{~W} \mathrm{~kg}^{-1}$.

and Braham 1991; Kristovich et al. 1999; Laird and Kristovich 2002); accordingly, these fluxes were used as a benchmark to assess the relative significance of $\mathrm{DTAP}_{h}$. To perform this comparison, lake surface heat fluxes were converted into an energy production rate (or power), equivalent to $\mathrm{DTAP}_{h}$, using mixed-layer similarity theory and a dimensionless energy dissipation rate of 0.5 from Kaimal et al. (1976). Both sensible and latent lake surface heat fluxes were included to account for convective invigoration through latent heat release. A scatterplot of DTAP $h$ versus lake surface power is presented in Fig. 3 (solid and dashed lines with slopes of unity and one-quarter, respectively, are included to facilitate comparison) and indicates that $\mathrm{DTAP}_{h}$ is a significant power source. This is especially true for snapshots associated with strong, deep CAA in the lower troposphere, when $\mathrm{DTAP}_{h}$ is typically maximized. The mean value of $\mathrm{DTAP}_{h}$ is approximately $29 \%$ the mean value of the lake surface power, and $\mathrm{DTAP}_{h}$ exceeds one-quarter of the lake surface power in 16 snapshots $(\sim 47 \%)$. In five snapshots $(\sim 15 \%)$, DTAP $_{h}$ exceeds one-half of the lake surface power, and in two snapshots, $\mathrm{DTAP}_{h}$ is greater than the lake surface power.

We next tested the correlation between $\mathrm{DTAP}_{h}$ and InPen $_{20}$. DTAP ${ }_{h}$ exhibits a strong and statistically significant correlation with $\operatorname{InPen}_{20}(r=0.77, p$ value $<$ 0.01). This strong relationship between $\mathrm{DTAP}_{h}$ and 
InPen $_{20}$ supports the hypothesis that CAA increasing with height (as captured by $\mathrm{DTAP}_{h}$ ) is invigorating the inland portions of LLAP bands and increasing their InPen.

\section{b. Empirical regression models for InPen}

Following our hypothesis-based exploration of InPen predictors in section $3 \mathrm{a}$, we added an empirical step of developing regression models for $\mathrm{InPen}_{20}$ and testing their predictive skill. To generate these models, we used stepwise regression (Wilks 2006), which is a systematic method for generating statistically significant multilinear regression models based on the incremental explanatory power of individual variables. An entrance $p$ value (sometimes referred to as the test rejection level) of 0.05 was used; this is the maximum $p$ value for a variable to be initially accepted into the model. We also used 0.05 as the removal $p$ value-the minimum $p$ value for a variable to subsequently be removed from the model during the iterative selection process. Resulting from the stepwise regression analysis was a series of InPen $_{20}$ prediction models (hereafter referred to as InPen models), in which each variable included is statistically significant (to at least the removal $p$ value) and each variable not included would not be statistically significant were it to be included.

After these InPen models were generated, we evaluated each model's robustness by testing it on independent data, using a block version of leave-one-out cross validation (Zhang 1993; Wilks 2006). LLAP-band snapshots were first grouped into 10 blocks, such that each LLAP-band block was separated by at least $24 \mathrm{~h}$ from every other block (in contrast to the 6-h minimum separation between snapshots). This process was used to separate groups of snapshots that occurred during distinct synoptic events, recognizing that individual synoptic events could exhibit different relationships between InPen and InPen predictors. Following the selection of these LLAP-band blocks, one block was left out and a multilinear regression model was developed from the remaining blocks (using the variables indicated by the initial stepwise regression) and then tested on the omitted block. This process was repeated for each block and used to generate cross-validated model statistics.

The results of the stepwise regression analyses are presented in Table 2 . Model 1 begins with only the potential predictors included under the advection-only hypothesis (as listed in Table 1), to test for the optimal, statistically significant combination of these variables. Ascent advection distance and fallout advection distance are treated as separate predictors to allow for individual scaling of each variable. In contrast, model 2
TABLE 2. Empirical InPen $_{20}$ prediction models selected by stepwise regression, using a test rejection level of 0.05 (see text for further information). The third column was computed from independent data using cross validation (explained in text). A (-) sign indicates the coefficient for that variable is negative; for thermal advection, a ( - ) sign indicates a positive relationship between InPen $_{20}$ and CAA at that level.

\begin{tabular}{|c|c|c|}
\hline Model No. & $\begin{array}{l}\text { Variables selected by stepwise } \\
\text { regression }\end{array}$ & $\begin{array}{c}\text { Variance } \\
\text { explained (\%) }\end{array}$ \\
\hline 1 & $\begin{array}{l}\text {-Ascent advection distance } \\
\text {-CBL depth (fallout advection } \\
\text { distance was rejected) }\end{array}$ & 45 \\
\hline 2 & $\begin{array}{l}\cdot \mathrm{DTAP}_{h} \\
\cdot \mathrm{CBL}_{\text {depth }}\end{array}$ & 62 \\
\hline 3 & $\begin{array}{l}\text {-(-) Thermal advection at } 850 \mathrm{hPa} \\
\text {-CBL depth }\end{array}$ & 61 \\
\hline 4 & $\begin{array}{l}\text {-(-) Thermal advection at } 900 \mathrm{hPa} \\
\text {-CBL depth }\end{array}$ & 67 \\
\hline 5 & $\begin{array}{l}\cdot(-) \text { Thermal advection at } \\
p_{Z_{i}}+25 \mathrm{hPa} \\
\cdot \mathrm{CBL} \text { depth }\end{array}$ & 76 \\
\hline
\end{tabular}

begins with all of the potential predictors from Table 1 (the results of using only predictors associated with either the inland plume-focusing hypothesis or the inland invigoration hypothesis added little new information and are omitted). Of these first two models, greater skill (evaluated as the cross-validated percentage of InPen $_{20}$ variance explained) is achieved by model 2 . Model 2 uses DTAP $_{h}$ and CBL depth as predictors and explains $62 \%$ of the $\operatorname{InPen}_{20}$ variance. Model 2 has a root-meansquare error (RMSE) of $36 \mathrm{~km}$ [a mean absolute error (MAE) of $29 \mathrm{~km}$ ].

We next investigated whether the predictive ability of $\mathrm{DTAP}_{h}$ could be captured by a simpler predictor that nonetheless controlled much of its variability. Based on the evidence that CAA may be associated with InPen, we computed vertical profiles of the correlation between thermal advection (as a function of NARR pressure level) and InPen; the results are presented in Fig. 4. InPen 10, InPen $_{20}$, and InPen $_{30}$ exhibit very similar profiles: correlation coefficients begin near -0.5 for the lowest adequately represented NARR levels, decrease with increasing height (decreasing pressure level) to reach their minima at $850 \mathrm{hPa}$, and increase rapidly with height above $825 \mathrm{hPa}$. The $850-\mathrm{hPa}$ minima indicate a strong, statistically significant relationship between CAA at this level and InPen $(r=-0.78, p$ value $<0.01$ for InPen $_{20}$ ).

The 850-hPa minima are especially interesting in view of the observation that $850 \mathrm{hPa}$ was near the top of the CBL for many LLAP-band snapshots. To further examine this finding, we computed the correlation 


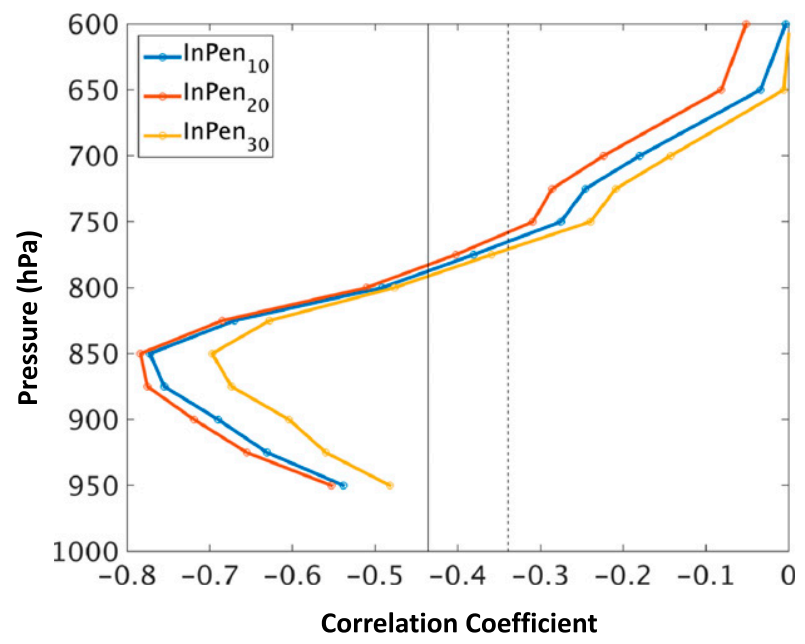

FIG. 4. Correlation coefficient between InPen and thermal advection (i.e., potential temperature advection) as a function of pressure level. The solid black line (dashed black line) indicates the value of the correlation coefficient corresponding to a $p$ value of 0.01 (0.05); correlation coefficients falling left of this line are statistically significant at the $99 \%(95 \%)$ confidence level. Note the pronounced minima at $850 \mathrm{hPa}$, indicating a strong correlation between InPen and CAA at this level. The minimum correlation coefficient (strongest correlation) in this plot is between thermal advection at $850 \mathrm{hPa}$ and $\mathrm{InPen}_{20}$, with a correlation coefficient of -0.78 . Data below $950 \mathrm{hPa}$ were not consistently available and were omitted.

between $\operatorname{InPen}_{20}$ and thermal advection at $p_{Z_{i}}$ (the NARR pressure level of $Z_{i}$ for each snapshot), and at specific NARR pressure increments above and below $p_{Z_{i}}$ (see Fig. 5). The strongest (most negative) correlation occurs at $p_{Z_{i}}+25 \mathrm{hPa}$ (i.e., $25 \mathrm{hPa}$ below $Z_{i}$ ) and is very similar to the $\mathrm{InPen}_{20}$-thermal advection correlation at $850 \mathrm{hPa}(r=-0.77, p$ value $<0.01)$.

To further investigate the strong correlations between InPen $_{20}$ and CAA at both absolute and $Z_{i}$-relative pressure levels, we combined the thermal advection at each of these levels with the potential predictors associated with the advection-only and plume-focusing hypotheses (see Table 1; $\mathrm{DTAP}_{h}$ was not included here since its performance was being compared to that of other thermal advection variables). Stepwise regression was then performed on each joint group, recognizing that one or another thermal advection variable could provide the most skill independent of that provided by the Table 1 predictors. The three most noteworthy resulting models are presented under models 3-5 in Table 2. Stepwise regression reveals models 3 and 4, which use thermal advection at absolute pressure levels, to be less successful than model 5 , which uses $Z_{i}$-relative data. Specifically, model 5 combines thermal advection at $p_{Z_{i}}+25 \mathrm{hPa}$ (i.e., $25 \mathrm{hPa}$ below $Z_{i}$ ) with $\mathrm{CBL}$ depth to

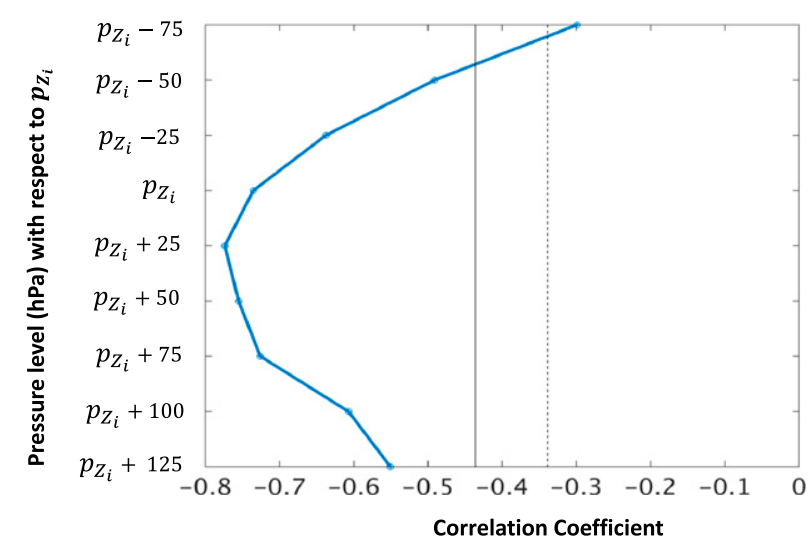

FIG. 5. Correlation coefficient between $\operatorname{InPen}_{20}$ and thermal advection (i.e., potential temperature advection) at $p_{Z_{i}}$ and at several pressure increments above and below $p_{Z_{i}}$. As in Fig. 4, the solid black line (dashed black line) indicates the value of the correlation coefficient corresponding to a $p$ value of 0.01 (0.05); correlation coefficients falling left of this line are statistically significant at the $99 \%(95 \%)$ confidence level. The minimum correlation coefficient (strongest correlation) in this plot is between $\mathrm{InPen}_{20}$ and the thermal advection at $p_{Z_{i}}+25 \mathrm{hPa}$ (i.e., $25 \mathrm{hPa}$ below $Z_{i}$ ), with a correlation coefficient of -0.77 .

achieve a strong prediction of $\operatorname{InPen}_{20}(76 \%$ of the observed $\mathrm{InPen}_{20}$ variance explained).

In fact, model 5 is noticeably more skillful in predicting InPen $_{20}$ than model 2 (which uses DTAP $_{h}$ and CBL depth); while model 5 explains $76 \%$ of the InPen $_{20}$ variance, model 2 explains only $62 \%$. This finding was not expected because $\mathrm{DTAP}_{h}$ quantifies the power available to inland LLAP bands through differential thermal advection, while thermal advection at $p_{Z_{i}}+$ $25 \mathrm{hPa}$ (hereafter termed upper-CBL thermal advection) offers only a rough indication of this power. Note, however, that both components of model 5 (upper-CBL thermal advection and CBL depth) are related to attributes of $\mathrm{DTAP}_{h}$. Moreover, using the ad hoc variables may bypass some of the issues involved with using coarse reanalyses to accurately compute $\mathrm{DTAP}_{h}$. The vertical resolution of the NARR may be insufficient to adequately resolve thermal advection profiles and render high-accuracy values of DTAP ${ }_{h}$. Noise introduced by inadequate vertical resolution would then reduce the predictive skill of DTAP ${ }_{h}$. In contrast, upper-CBL thermal advection is measured at a single pressure level (albeit different for each snapshot) and is likely to be less sensitive to vertical resolution.

Specifically, the model 5 prediction of $\operatorname{InPen}_{20}$ is given by the following equation:

$$
\begin{aligned}
\text { InPen }_{20}= & \text { intercept }+a \times(\mathrm{CBL} \text { depth })-b \\
& \times\left(\text { thermal advection at } p_{Z_{i}}+25 \mathrm{hPa}\right),
\end{aligned}
$$




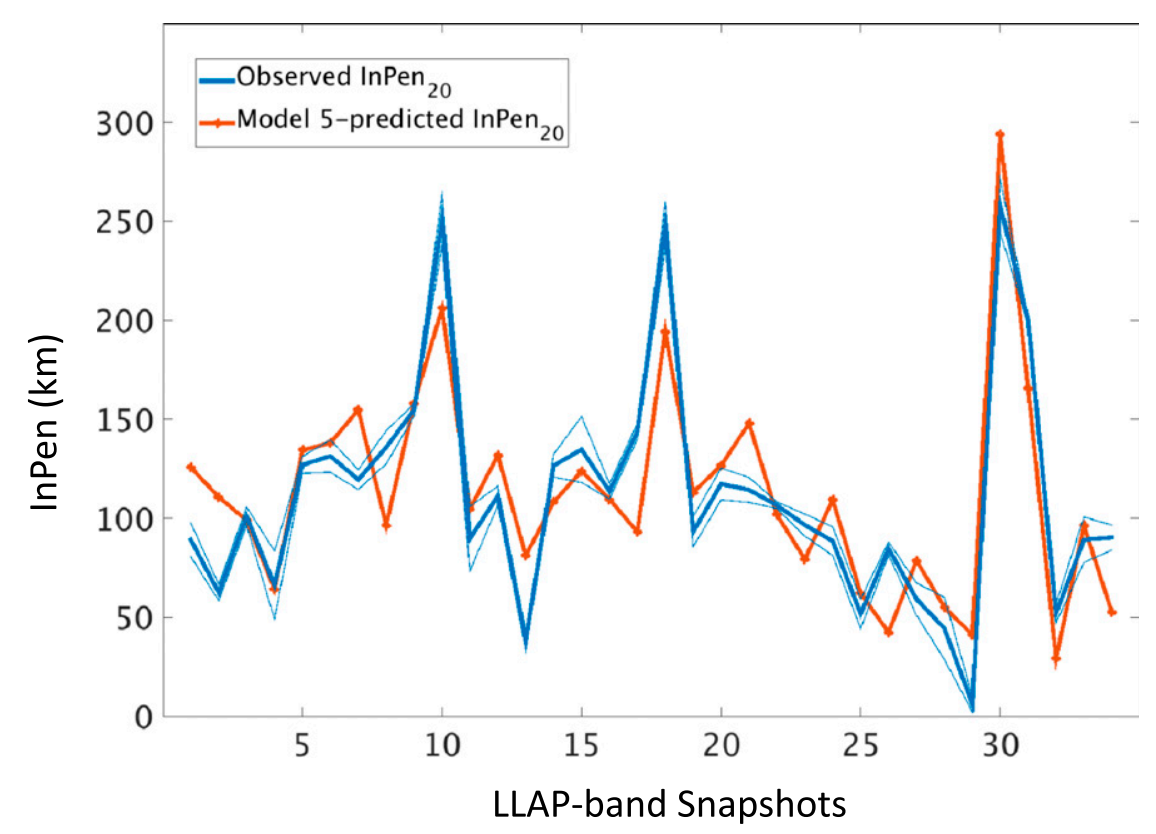

FIG. 6. Plot of observed InPen 20 and the model 5 prediction of $\operatorname{InPen}_{20}$ for all LLAP-band snapshots used in the study. The model 5-predicted InPen $_{20}$ series is obtained from a crossvalidated form of model 5 [Eq. (6)], as described in the text. The thin blue lines bracketing the observed InPen $_{20}$ series represent \pm 1 mean absolute deviation (MAD) of each InPen $_{20}$ measurement (i.e., MADs are calculated and plotted for each snapshot). Model 5 explains $76 \%$ of the variance in observed InPen $_{20}$ and has an RMSE of $28 \mathrm{~km}$ (MAE of $24 \mathrm{~km}$ ).

where $\operatorname{InPen}_{20}$ is in kilometers, intercept $=-15.5 \mathrm{~km}$, $a=81.6 \mathrm{~km} \mathrm{~km}^{-1}$, and $b=36.8 \times 10^{4} \mathrm{~km} \mathrm{~s} \mathrm{~K}^{-1}$ (the standard errors of $a$ and $b$ are $15.2 \mathrm{~km} \mathrm{~km}^{-1}$ and $5.62 \times 10^{4} \mathrm{~km} \mathrm{~s} \mathrm{~K}^{-1}$, respectively). When tested on independent data using cross validation (as explained earlier in the section), this model explains $76 \%$ of the observed InPen ${ }_{20}$ variance and has an RMSE of $28 \mathrm{~km}$ (MAE of $24 \mathrm{~km}$ ). Predicted InPen $_{20}$, using the crossvalidated form of model 5 , is plotted alongside observed InPen $_{20}$ in Fig. 6. A comparison of the predicted and observed values reveals that model 5 shows skill for a broad range of observed $\operatorname{InPen}_{20}$ values and is largely successful at capturing relative maxima and minima in the observed series.

\section{Conclusions}

An examination of three hypotheses for the inland penetration of long-lake-axis-parallel (LLAP) snowbands reveals new insights into environmental predictors of the inland penetration of LLAP-band radar echoes (InPen). Investigation of the advectiononly hypothesis reveals several advection-related variables and thermodynamic variables, notably convective boundary layer (CBL) depth, which exhibit moderate-to-strong correlations with InPen at the
20-dBZ level ( $\operatorname{InPen}_{20}$; see Table 1). However, neither the advection-only hypothesis nor the inland plume-focusing hypothesis appears capable of fully explaining $\mathrm{InPen}_{20}$.

Additional insight into the factors modulating InPen is offered through an investigation of the inland invigoration hypothesis. The findings suggest that boundary layer destabilization occurring when coldair advection (CAA) increases with height is a significant inland power source for preexisting LLAP bands. This hypothesis is further supported by a comparison between differential horizontal thermal advection power $\left(\mathrm{DTAP}_{h}\right)$-a measure of the power produced by vertically differential horizontal thermal advection (both overlake and inland) - and the power supplied through lake surface heat fluxes. This comparison reveals that $\mathrm{DTAP}_{h}$, though typically smaller than lake surface power production, is a significant power source. Moreover, a statistical model combining $\mathrm{DTAP}_{h}$ and CBL depth is reasonably skillful in predicting InPen. Nevertheless, this model is outperformed by models using empirical combinations of upper-CBL thermal advection and CBL depth (possibly because the vertical resolution of the NARR is insufficient for high-accuracy DTAP $_{h}$ calculations). 
The indicated approach to forecasting InPen is based on the assumption that the general ingredients for LLAP-band formation are already present-namely, adequate lake-effect forcing and moderate-to-strong boundary layer winds approximately aligned with the long lake axis and reasonably well aligned vertically. After these conditions are satisfied, model 5 [as presented in Eq. (6)] predicts increased $\operatorname{InPen}_{20}$ when numerical weather prediction models forecast a deeper boundary layer and/or increased CAA in the top portion of the boundary layer. Model 5 explains $76 \%$ of the observed $\mathrm{InPen}_{20}$ variance when tested on independent data and has an RMSE of $28 \mathrm{~km}$. In addition, combinations of CBL depth and thermal advection at other levels near $Z_{i}$ (as well as at $850 \mathrm{hPa}$ ) are only moderately less skillful than model 5 at predicting InPen $_{20}$. These findings indicate that a simple model based only on CBL depth and upper-CBL thermal advection can provide important guidance to forecasts of InPen. We recommend that future studies extend these results by testing them on various operational models.

Finally, we mention the complementary relationship between this work and that of Villani et al. (2017). A key finding of Villani et al. (2017) is the relationship between inland extent and the presence of a multilake connection, while a key result of the present study is the link between InPen and CAA in the upper CBL. Although the InPen and inland extent variables are notably nonidentical-as are other aspects of the methodologies used in the two studies - these findings, taken together, hint that both a multilake connection and upper-CBL CAA may be important for InPen/inland extent. We recommend that future studies synthesize these results and test their generality for various InPen/inland extent definitions, for other lakes, and for additional observation periods.

Acknowledgments. We gratefully acknowledge the entire team of OWLeS scientists and students for their dedicated field work under challenging conditions. We thank Yvette Richardson, Peter Bannon, Jack Langelaan, David Stauffer, Michael Jurewicz, Samuel Haimov, Jeffrey French, Neil Laird, Dave Kristovich, and Tim Hewson for many helpful discussions and suggestions. Insightful reviews by Jim Steenburgh, Editor Matthew J. Bunkers, and two anonymous reviewers greatly improved the quality of this manuscript. Special thanks are extended to the EOL of NCAR for maintaining the OWLeS data repository. We thank Kyle Imhoff for helping us access the NARR data. This work was funded by National Science Foundation Grants AGS-1259011 and AGS-1259020.

\section{APPENDIX}

\section{Derivation of DTAP}

Buoyancy to drive lake-effect convection is generated from a combination of three sources: environmental diabatic processes (such as surface buoyancy flux and radiative flux convergence), diabatic processes in convective parcels (such as latent heat release), and destabilization of the environment through differential thermal advection (by both horizontal and vertical components of the synoptic-scale wind). Specifically, during the satellite survey referenced in section $3 \mathrm{a}(3)$, differential thermal advection by the horizontal components of the synoptic-scale wind appeared to be associated with InPen. To obtain an expression for differential thermal advection power (DTAP), we begin by defining the integrated buoyancy over an arbitrary layer for a parcel originating from the lower boundary:

$$
\begin{aligned}
\mathrm{IB}_{l} & \cong g \int_{z_{l}}^{z_{u}} \frac{\theta_{l}+\mathrm{Dia}-\bar{\theta}}{\bar{\theta}} d z \\
& =g \int_{z_{l}}^{z_{u}} \frac{\theta_{l}-\bar{\theta}}{\bar{\theta}} d z+g \int_{z_{l}}^{z_{u}} \frac{\mathrm{Dia}}{\bar{\theta}} d z,
\end{aligned}
$$

where $g$ is the gravitational constant; $z_{l}$ and $z_{u}$ are arbitrary lower and upper boundaries, respectively (further discussed below); $\mathrm{IB}_{l}$ is the integrated $z_{l}$-based buoyancy (in units of specific energy, $\mathrm{J} \mathrm{kg}^{-1}$ or $\mathrm{m}^{2} \mathrm{~s}^{-2}$ ), $\theta_{l}$ is the potential temperature at $z_{l}$, Dia is the cumulative change in potential temperature of the lifted parcel due to all diabatic processes, and $\bar{\theta}$ is the potential temperature as a function of height, $z$ (i.e., $\bar{\theta}$ is the environmental profile of potential temperature). The first term on the right-hand side of Eq. (A1) includes the effects of both advective and diabatic environmental processes, while the second term captures the effect of diabatic processes within the parcel. Thus, the righthand-side formulation of $\mathrm{IB}_{l}$ allows us to begin the process of separating the effects of differential thermal advection from all diabatic effects.

Recalling that diabatic effects within the parcel are captured in the Dia term, the term $\theta_{l}-\bar{\theta}$ can be expressed as $-\int_{z_{l}}^{z}(\partial \bar{\theta} / \partial \delta) d \delta$, where $\delta$ is a dummy height variable. Then, Eq. (A1) may be rewritten as

$$
\mathrm{IB}_{l} \cong-g \int_{z_{l}}^{z_{u}} \frac{1}{\bar{\theta}}\left(\int_{z_{l}}^{z} \frac{\partial \bar{\theta}}{\partial \delta} d \delta\right) d z+g \int_{z_{l}}^{z_{u}} \frac{\mathrm{Dia}}{\bar{\theta}} d z
$$

We next make the approximation $1 / \bar{\theta} \approx 1 /\langle\bar{\theta}\rangle$, where $\langle\bar{\theta}\rangle$ is the layer-averaged potential temperature between $z_{l}$ 
and $z_{u}$. For a convectively mixed layer, the error introduced by this approximation is negligible. Thus, Eq. (A2) becomes

$\mathrm{IB}_{l} \cong-\frac{g}{\langle\bar{\theta}\rangle} \int_{z_{l}}^{z_{u}}\left(\int_{z_{l}}^{z} \frac{\partial \bar{\theta}}{\partial \delta} d \delta\right) d z+\frac{g}{\langle\bar{\theta}\rangle} \int_{z_{l}}^{z_{u}}$ Dia $d z$

We now consider the time rate of change of $\mathrm{IB}_{l}$, which has the units of specific power or specific energy production ( $\mathrm{W} \mathrm{kg}^{-1} \mathrm{or} \mathrm{m}^{2} \mathrm{~s}^{-3}$ ). Taking $\partial / \partial t$ of Eq. (A3) and switching the order of the partial derivatives in the first term on the right-hand side yields

$$
\begin{aligned}
\frac{\partial}{\partial t}\left(\mathrm{IB}_{l}\right) \cong & -\frac{g}{\langle\bar{\theta}\rangle} \int_{z_{l}}^{z_{u}}\left[\int_{z_{l}}^{z} \frac{\partial}{\partial \delta}\left(\frac{\partial \theta}{\partial t}\right) d \delta\right] d z \\
& +\frac{g}{\langle\bar{\theta}\rangle} \int_{z_{l}}^{z_{u}} \frac{\partial \mathrm{Dia}}{\partial t} d z .
\end{aligned}
$$

Next, we substitute $\partial \theta / \partial t=-\mathbf{V} \cdot \nabla \theta+Q$, where $-\mathbf{V} \cdot \nabla \theta$ is the three-dimensional potential temperature advection as a function of $z$, and $Q$ is the environmental diabatic heating rate as a function of $z$. This substitution allows Eq. (A4) to be rewritten as

$$
\begin{aligned}
\frac{\partial}{\partial t}\left(\mathrm{IB}_{l}\right) \cong & \frac{g}{\langle\bar{\theta}\rangle} \int_{z_{l}}^{z_{u}}\left[\int_{z_{l}}^{z} \frac{\partial}{\partial \delta}(\mathbf{V} \cdot \nabla \theta-Q) d \delta\right] d z \\
& +\frac{g}{\langle\bar{\theta}\rangle} \int_{z_{l}}^{z_{u}} \frac{\partial \mathrm{Dia}}{\partial t} d z .
\end{aligned}
$$

Assuming $\partial / \partial \delta(\mathbf{V} \cdot \nabla \theta-Q)$ is a continuous function, the fundamental theorem of calculus may be applied to the expression within the square brackets in Eq. (A5), resulting in

$$
\begin{aligned}
\int_{z_{l}}^{z} \frac{\partial}{\partial \delta}(\mathbf{V} \cdot \nabla \theta-Q) d \delta & =\left.(\mathbf{V} \cdot \nabla \theta-Q)\right|_{z_{l}} ^{z} \\
& =\mathbf{V} \cdot \nabla \theta-(\mathbf{V} \cdot \nabla \theta)_{l}+Q_{l}-Q,
\end{aligned}
$$

where $(\mathbf{V} \cdot \nabla \theta)_{l}$ and $Q_{l}$ are evaluated at $z_{l}$. Substituting Eq. (A6) into Eq. (A5) and rearranging yields

$$
\begin{aligned}
\frac{\partial}{\partial t}\left(\mathrm{IB}_{l}\right) \cong & \frac{g}{\langle\bar{\theta}\rangle} \int_{z_{l}}^{z_{u}}\left[\mathbf{V} \cdot \nabla \theta-(\mathbf{V} \cdot \nabla \theta)_{l}\right] d z \\
& +\frac{g}{\langle\bar{\theta}\rangle} \int_{z_{l}}^{z_{u}}\left(Q_{l}-Q\right) d z+\frac{g}{\bar{\theta}} \int_{z_{l}}^{z_{u}} \frac{\partial \mathrm{Dia}}{\partial t} d z .
\end{aligned}
$$

At this point we have succeeded in separating the power available to drive lake-effect convection into the three components noted at the start: destabilization of the environment through differential thermal advection, environmental diabatic processes, and diabatic processes within convective parcels. DTAP is defined as the maximum value, within the CBL, of the first of these three terms:

$\mathrm{DTAP} \equiv \max _{\mathrm{CBL}}\left\{\frac{g}{\bar{\theta}} \int_{z_{l}}^{z_{u}}\left[\mathbf{V} \cdot \nabla \theta-(\mathbf{V} \cdot \nabla \theta)_{l}\right] d z\right\}$,

where $\max _{C B L}$ indicates the maximum value within the CBL of the expression within the curly braces. The maximum value is determined by checking all possible combinations of $z_{l}$ and $z_{u}$, such that $z_{l}<z_{u} \leq Z_{i}$.

\section{REFERENCES}

Agee, E. M., and S. R. Gilbert, 1989: An aircraft investigation of mesoscale convection over Lake Michigan during the 10 January 1984 cold air outbreak. J. Atmos. Sci., 46, 18771897, https://doi.org/10.1175/1520-0469(1989)046<1877: AAIOMC $>2.0 . \mathrm{CO} ; 2$.

Ballentine, R. J., A. J. Stamm, E. E. Chermack, G. P. Byrd, and D. Schleede, 1998: Mesoscale model simulation of the 45 January 1995 lake-effect snowstorm. Wea. Forecasting, 13, 893-920, https://doi.org/10.1175/1520-0434(1998)013<0893: MMSOTJ $>2.0 . \mathrm{CO} ; 2$.

Banacos, P. C., and M. L. Ekster, 2010: The association of the elevated mixed layer with significant severe weather events in the northeastern United States. Wea. Forecasting, 25, 10821102, https://doi.org/10.1175/2010WAF2222363.1.

Barr, A. G., and A. K. Betts, 1997: Radiosonde boundary layer budgets above a boreal forest. J. Geophys. Res., 102D, 29205 29212, https://doi.org/10.1029/97JD01105.

Baxter, M. A., C. E. Graves, and J. T. Moore, 2005: A climatology of snow-to-liquid ratio for the contiguous United States. Wea. Forecasting, 20, 729-744, https://doi.org/10.1175/WAF856.1.

Bergmaier, P. T., B. Geerts, L. S. Campbell, and W. J. Steenburgh, 2017: The OWLeS IOP2b lake-effect snowstorm: Dynamics of the secondary circulation. Mon. Wea. Rev., 145, 2437-2459, https://doi.org/10.1175/MWR-D-16-0462.1.

Black, T., 1994: The new NMC mesoscale Eta Model: Description and forecast examples. Wea. Forecasting, 9, 265-278, https:// doi.org/10.1175/1520-0434(1994)009<0265:TNNMEM> 2.0. $\mathrm{CO} ; 2$

Byrd, G. P., R. A. Anstett, J. E. Heim, and D. M. Usinski, 1991: Mobile sounding observations of lake-effect snowbands in western and central New York. Mon. Wea. Rev., 119, 2323-2332, https://doi.org/10.1175/1520-0493(1991)119<2323: MSOOLE $>2.0 . \mathrm{CO} ; 2$.

Campbell, L. S., and W. J. Steenburgh, 2017: The OWLeS IOP2b lake-effect snowstorm: Mechanisms contributing to the Tug Hill precipitation maximum. Mon. Wea. Rev., 145, 2461-2478, https://doi.org/10.1175/MWR-D-16-0461.1.

,-- , P. G. Veals, T. W. Letcher, and J. R. Minder, 2016: Lake-effect mode and precipitation enhancement over the Tug Hill Plateau during OWLeS IOP2b. Mon. Wea. Rev., 144, 1729-1748, https://doi.org/10.1175/MWR-D-15-0412.1.

Chang, S., and R. R. Braham Jr., 1991: Observational study of a convective internal boundary layer over Lake Michigan. J. Atmos. Sci., 48, 2265-2279, https://doi.org/10.1175/ 1520-0469(1991)048<2265:OSOACI >2.0.CO;2. 
Dewey, K. F., 1979: An objective forecast method developed for Lake Ontario induced snowfall systems. J. Appl. Meteor., 18, 787-793, https://doi.org/10.1175/1520-0450(1979) $018<0787$ :AOFMDF $>2.0$.CO;2.

Ek, M. B., K. E. Mitchell, Y. Lin, E. Rogers, P. Grunmann, V. Koren, G. Gayno, and J. D. Tarpley, 2003: Implementation of Noah land surface model advances in the National Centers for Environmental Prediction operational mesoscale Eta Model. J. Geophys. Res., 108, 8851, https://doi.org/10.1029/ 2002JD003296.

Gensini, V. A., and W. S. Ashley, 2011: Climatology of potentially severe convective environments from North American Regional Reanalysis. Electron. J. Severe Storms Meteor., 6 (8), http://www.ejssm.org/ojs/index.php/ejssm/article/ viewArticle/85.

Hjelmfelt, M. R., 1990: Numerical study of the influence of environmental conditions on lake-effect snowstorms over Lake Michigan. Mon. Wea. Rev., 118, 138-150, https://doi.org/ 10.1175/1520-0493(1990)118<0138:NSOTIO > 2.0.CO;2.

Holroyd, E. W., III, 1971: Lake-effect cloud bands as seen from weather satellites. J. Atmos. Sci., 28, 1165-1170, https://doi.org/10.1175/ 1520-0469(1971)028<1165:LECBAS > 2.0.CO;2.

Janjić, Z. I., 1994: The step-mountain eta coordinate model: Further developments of the convection, viscous sublayer, and turbulence closure schemes. Mon. Wea. Rev., 122, 927-945, https://doi.org/10.1175/1520-0493(1994) 122<0927:TSMECM > 2.0.CO;2.

Jiusto, J. E., and M. L. Kaplan, 1972: Snowfall from lake-effect storms. Mon. Wea. Rev., 100, 62-66, https://doi.org/10.1175/ 1520-0493(1972) $100<0062:$ SFLS $>2.3$. CO 2 .

Kaimal, J. C., J. C. Wyngaard, D. A. Haugen, O. R. Coté, and Y. Izumi, 1976: Turbulence structure in the convective boundary layer. J. Atmos. Sci., 33, 2152-2169, https://doi.org/ 10.1175/1520-0469(1976)033<2152:TSITCB > 2.0.CO;2.

Kelly, R. D., 1986: Mesoscale frequencies and seasonal snowfalls for different types of Lake Michigan snow storms. J. Climate Appl. Meteor., 25, 308-312, https://doi.org/ 10.1175/1520-0450(1986)025<0308:MFASSF>2.0.CO;2.

Kristovich, D. A. R., 1993: Mean circulations of boundary-layer rolls in lake-effect snow storms. Bound.-Layer Meteor., 63, 293-315, https://doi.org/10.1007/BF00710463.

_ cloudiness: Influences of lake surface temperature and upwind conditions. Wea. Forecasting, 13, 811-821, https://doi.org/ 10.1175/1520-0434(1998)013<0811:OOWLEC >2.0.CO;2.

,,-- M. R. Hjelmfelt, R. G. Derickson, and K. A. Cooper, 1999: Transitions in boundary layer meso- $\gamma$ convective structures: An observational case study. Mon. Wea. Rev., 127, 2895-2909, https://doi.org/10.1175/1520-0493(1999) $127<2895$ :TIBLMC $>2.0$. CO 2 .

,-- , and 2003: Convective evolution across Lake Michigan during a widespread lake-effect snow event. Mon. Wea. Rev., 131, 643-655, https://doi.org/10.1175/1520-0493(2003) 131<0643:CEALMD > 2.0.CO;2.

— tems field campaign: Scientific and educational adventures to further our knowledge and prediction of lake-effect storms. Bull. Amer. Meteor. Soc., 98, 315-332, https://doi.org/10.1175/ BAMS-D-15-00034.1.

Laird, N. F., and D. A. R. Kristovich, 2002: Variations of sensible and latent heat fluxes from a Great Lakes buoy and associated synoptic weather patterns. J. Hydrometeor., 3, 3-12, https:// doi.org/10.1175/1525-7541(2002)003<0003:VOSALH>2.0.CO;2.
,-- , and J. E. Walsh, 2003a: Idealized model simulations examining the mesoscale structure of winter lake-effect circulations. Mon. Wea. Rev., 131, 206-221, https://doi.org/ 10.1175/1520-0493(2003)131<0206:IMSETM>2.0.CO;2.

_ J. E. Walsh, and D. A. R. Kristovich, 2003b: Model simulations examining the relationship of lake-effect morphology to lake shape, wind direction, and wind speed. Mon. Wea. Rev., 131, 2102-2111, https://doi.org/10.1175/1520-0493(2003) $131<2102$ :MSETRO > 2.0.CO;2.

Lenschow, D. H., 1973: Two examples of planetary boundary layer modification over the Great Lakes. J. Atmos. Sci., 30, 568-581, https://doi.org/10.1175/1520-0469(1973)030<0568: TEOPBL $>2.0 . \mathrm{CO} ; 2$.

Lombardo, K. A., and B. A. Colle, 2011: Convective storm structures and ambient conditions associated with severe weather over the northeast United States. Wea. Forecasting, 26, 940956, https://doi.org/10.1175/WAF-D-11-00002.1.

Markowski, P., and Y. Richardson, 2010: Mesoscale Meteorology in Midlatitudes. Wiley-Blackwell, $407 \mathrm{pp}$.

Mellor, G. L., and T. Yamada, 1974: A hierarchy of turbulence closure models for planetary boundary layers. J. Atmos. Sci., 31, 1791-1806, https://doi.org/10.1175/1520-0469(1974) 031<1791:AHOTCM>2.0.CO;2.

— and - 1982: Development of a turbulence closure model for geophysical fluid problems. Rev. Geophys. Space Phys., 20, 851-875, https://doi.org/10.1029/RG020i004p00851.

Mesinger, F., Z. I. Janjić, S. Ničković, D. Gavrilov, and D. G. Deaven, 1988: The step-mountain coordinate: Model description and performance for cases of alpine lee cyclogenesis and for a case of an Appalachian redevelopment. Mon. Wea. Rev., 116, 1493-1518, https://doi.org/10.1175/1520-0493(1988) 116<1493:TSMCMD $>2.0$. CO;2.

_ Bull. Amer. Meteor. Soc., 87, 343-360, https://doi.org/10.1175/ BAMS-87-3-343.

Miles, N. L., and J. Verlinde, 2005a: Observations of transient linear organization and nonlinear scale interactions in lakeeffect clouds. Part I: Transient linear organization. Mon. Wea. Rev., 133, 677-691, https://doi.org/10.1175/MWR-2879.1.

$\longrightarrow$, and,$- 2005 \mathrm{~b}$ : Observations of transient linear organization and nonlinear scale interactions in lake-effect clouds. Part II: Nonlinear scale interactions. Mon. Wea. Rev., 133, 692-706, https://doi.org/10.1175/MWR-2880.1.

Minder, J. R., T. W. Letcher, L. S. Campbell, P. G. Veals, and W. J. Steenburgh, 2015: The evolution of lake-effect convection during landfall and orographic uplift as observed by profiling radars. Mon. Wea. Rev., 143, 4422-4442, https://doi.org/ 10.1175/MWR-D-15-0117.1.

Niziol, T. A., 1987: Operational forecasting of lake-effect snowfall in western and central New York. Wea. Forecasting, 2, 310-321, https://doi.org/10.1175/1520-0434(1987)002<0310: OFOLES $>2.0 . \mathrm{CO} ; 2$.

— W. R. Snyder, and J. S. Waldstreicher, 1995: Winter weather forecasting throughout the eastern United States. Part IV: Lake effect snow. Wea. Forecasting, 10, 61-77, https://doi.org/ 10.1175/1520-0434(1995)010<0061:WWFTTE >2.0.CO;2.

Orlanski, I., 1975: A rational subdivision of scales of atmospheric processes. Bull. Amer. Meteor. Soc., 56, 527-530, https://doi.org/10.1175/1520-0477-56.5.527.

Passarelli, R. E., Jr., and R. R. Braham Jr., 1981: The role of the winter land breeze in the formation of Great Lake snow storms. Bull. Amer. Meteor. Soc., 62, 482-491, https://doi.org/ 10.1175/1520-0477(1981)062<0482:TROTWL > 2.0.CO;2. 
Peace, R. L., and R. B. Sykes, 1966: Mesoscale study of a lake-effect snowstorm. Mon. Wea. Rev., 94, 495-507, https://doi.org/ 10.1175/1520-0493(1966)094<0495:MSOALE>2.3.CO;2.

Phillips, D. W., 1972: Modification of surface air over Lake Ontario in winter. Mon. Wea. Rev., 100, 662-670, https://doi.org/ 10.1175/1520-0493(1972)100<0662:MOSAOL > 2.3.CO;2.

Rasmussen, R., M. Dixon, S. Vasiloff, F. Hage, S. Knight, J. Vivekanandan, and M. Xu, 2003: Snow nowcasting using a real-time correlation of radar reflectivity with snow gauge accumulation. J. Appl. Meteor., 42, 20-36, https://doi.org/ 10.1175/1520-0450(2003)042<0020:SNUART >2.0.CO;2.

Reinking, R. F., and Coauthors, 1993: The Lake Ontario Winter Storms (LOWS) project. Bull. Amer. Meteor. Soc., 74, 18281849, https://doi.org/10.1175/1520-0477-74-10-1828.

Rogers, E., M. Ek, Y. Lin, K. Mitchell, D. Parrish, and G. DiMego, 2001: Changes to the NCEP Meso Eta analysis and forecast system: Assimilation of observed precipitation, upgrades to land-surface physics, modified 3DVAR analysis. NWS Tech. Procedures Bull. 473, 14 pp.

Schmid, P., and D. Niyogi, 2012: A method for estimating planetary boundary layer heights and its application over the ARM Southern Great Plains site. J. Atmos. Oceanic Technol., 29, 316-322, https://doi.org/10.1175/JTECH-D-11-00118.1.

Seibert, P., F. Beyrich, S.-E. Gryning, S. Joffre, A. Rasmussen, and P. Tercier, 2000: Review and intercomparison of operational methods for the determination of mixing height. Atmos. Environ., 34, 1001-1027, https://doi.org/10.1016/S1352-2310(99) 00349-0.

Sousounis, P. J., 1993: A numerical investigation of wind speed effects on lake-effect storms. Bound.-Layer Meteor., 64, 261290, https://doi.org/10.1007/BF00708966.

Steenburgh, W. J., and L. S. Campbell, 2017: The OWLeS IOP2b lake-effect snowstorm: Shoreline geometry and the mesoscale forcing of precipitation. Mon. Wea. Rev., 145, 2421-2436, https://doi.org/10.1175/MWR-D-16-0460.1.

Steiger, S. M., R. Hamilton, J. Keeler, and R. E. Orville, 2009: Lake-effect thunderstorms in the lower Great Lakes.
J. Appl. Meteor. Climatol., 48, 889-902, https://doi.org/ 10.1175/2008JAMC1935.1.

— , and Coauthors, 2013: Circulations, bounded weak echo regions, and horizontal vortices observed within long-lakeaxis-parallel-lake-effect storms by the Doppler on Wheels. Mon. Wea. Rev., 141, 2821-2840, https://doi.org/10.1175/ MWR-D-12-00226.1.

Stull, R. B., 1988: An Introduction to Boundary Layer Meteorology. Kluwer Academic, 666 pp.

Thiébaux, H. J., E. Rogers, W. Wang, and B. Katz, 2003: A new high-resolution blended real-time global sea surface temperature analysis. Bull. Amer. Meteor. Soc., 84, 645-656, https:// doi.org/10.1175/BAMS-84-5-645.

Vasiloff, S., 2002: Investigation of a WSR-88D Z-R relation for snowfall in northern Utah. 16th Conf. on Hydrology, Orlando, FL, Amer. Meteor. Soc., 3.18, https://ams.confex.com/ams/ annual2002/webprogram/Paper26411.html.

Veals, P. G., and W. J. Steenburgh, 2015: Climatological characteristics and orographic enhancement of lake-effect precipitation east of Lake Ontario and over the Tug Hill Plateau. Mon. Wea. Rev., 143, 3591-3609, https://doi.org/10.1175/ MWR-D-15-0009.1.

Villani, J. P., M. L. Jurewicz Sr., and K. Reinhold, 2017: Forecasting the inland extent of lake effect snow bands downwind of Lake Ontario. J. Oper. Meteor., 5, 53-70, https://doi.org/ 10.15191/nwajom.2017.0505.

Welsh, D., B. Geerts, J. Minder, J. Steenburgh, P. Bergmaier, X. Jing, and L. Campbell, 2016: Understanding heavy lakeeffect snowfall: The vertical structure of radar reflectivity in a deep snowband over and downwind of Lake Ontario. Mon. Wea. Rev., 144, 4221-4244, https://doi.org/10.1175/ MWR-D-16-0057.1.

Wilks, D. S., 2006: Statistical Methods in the Atmospheric Sciences. 2nd ed. Elsevier, 627 pp.

Zhang, P., 1993: Model selection via multifold cross validation. Ann. Stat., 21, 299-313, https://doi.org/10.1214/aos/ 1176349027. 